\title{
Synthesis, Antiviral Evaluation and Molecular Docking Studies of Azo
}

\section{Compounds}

\author{
Muhammad Ashfaq ${ }^{* 1,3}$, Mirza Imran Shahzad ${ }^{2}$, Tehreem Tahir ${ }^{3}$ \\ ${ }^{1}$ Department of Chemistry, Faculty of Science, The Islamia University of Bahawalpur, Bahawalpur \\ 63100, Pakistan. Email: chashfaqiub@yahoo.com \\ ${ }^{2}$ University College of Veterinary and Animal Sciences, Baghdad-ul-Jadeed Campus, The Islamia \\ University of Bahawalpur, Bahawalpur 63100, Pakistan. Email: mirza.imran@iub.edu.pk \\ ${ }^{3}$ Department of Biochemistry \& Biotechnology, Faculty of Science, The Islamia University of \\ Bahawalpur, Bahawalpur 63100, Pakistan. Email: tahreemtahir90@gmail.com
}

*Corresponding author: Muhammad Ashfaq, email: chashfaqiub@yahoo.com, cell no: +923006829307. 


\section{Abstract}

Objective: Owing to the versatile and promising bioactive potential of azo dyes, the present study describes the synthesis, antiviral evaluation and molecular docking study of most potent compound of azo series.

Methods: The synthesis of title compounds was done by the coupling reaction of diazonium salt solutions with active methylene (1,3-dioxolane and benzimidazole), to yield [(E)-1-(1,3-dioxolan-2yl)-2-phenyldiazene] (1), [(E)-1-(1,3-dioxolan-2-yl)-2-(4-methylphenyl)diazene] (2), 2-[(E)-phenyldiazenyl]-1 $H$-benzimidazole] (3) , [(E)-1-(1,3-dioxolan-2-yl)-2-(4-ethylphenyl)diazene] (4) and [(E)-1-(1,3-dioxolan-2-yl)-2-(2-methylphenyl)diazene] (5). The structures of newly synthesized molecules were elucidated by spectroscopic techniques $\left({ }^{1} \mathrm{H}\right.$ NMR and FT-IR). The In Ovo screening of compounds against avian influenza virus (AIV) H9N2 strain and newcastle disease virus (NDV) Lasota strain was done.

Results: The evaluation data suggested that azo compound (5) exhibited highest anti-AIV and antiNDV activity (100\% inhibition at $0.1 \mathrm{mg} / 100 \mu \mathrm{L})$ compared to the other azo compounds which showed less activity at given concentration. Docking study further suggested that azo compound (5) binds with the active site residues of viral proteins with good binding affinity (-6.9 and -8.0 $\mathrm{kcal} / \mathrm{mol}$ ) compared to the standard oseltamivir due to the substitution of $-\mathrm{CH}_{3}$ group at ortho position on phenyl ring.

Conclusion: Hence, based on this investigation, it was inferred that azo compound (5) may serve as a novel scaffold for designing more active antiviral agents.

\section{Keywords}

Antiviral agents, Avian Influenza, Newcastle Disease, Azo derivatives, Drug discovery 


\section{INTRODUCTION}

Viruses of Orthomyxoviridae and Paramyxoviridae families are highly contagious and epidemic in nature that cause respiratory infections in birds and mammals leading to the health and socioeconomic threats 1,2 . There are two major surface glycoproteins, Hemagglutinin (HA) and Neuraminidase (NA) in orthomyxoviruses while the paramyxoviruses have a hemagglutininneuraminidase $(\mathrm{HN})$ protein and a fusion $(\mathrm{F})$ protein, which are responsible for providing the attachment and penetration of viruses into target cell, thus provide potential targets for structurebased drug design 2,3. Currently, there are two ways to reduce the impact of viral infections i.e. vaccination or antiviral drug therapy ${ }^{4,5}$. However, there are limitations associated with vaccines, as their development has been greatly hindered by the high mutability of the virus and its developing subtypes 6,7, which is nearly impossible to supply vaccines in adequate amount while antiviral drugs can meet the need of the pandemic disaster ${ }^{8}$. There are two classes of anti-influenza drugs up to now available in market, one which are targeting the M2 ion channel (Adamantanes) and secondly that inhibit neuraminidase (Oseltamivir and Zanamivir) for influenza A and influenza B infections ${ }^{9-12}$. Neuraminidase inhibitors have great potential as sensitive anti-influenza drugs over the adamantanes due to their activity, improved safety profile and highly conserved active pocket in mostly influenza viral strains ${ }^{13,14}$. Many studies have been established to explore the inhibitory activities of compounds derived from natural sources and synthetic drugs ${ }^{14-16}$. Among them, plant derived neuraminidase inhibitors show lesser activity compared to the synthetic drugs. Therefore, there is a constant need of efficient and novel synthetic therapeutic compounds, as synthetic compounds are the integral components of drug discovery pipeline that are not compromised by the emergence of rapid drug resistant viral strains, of higher efficacy and minimal side effects ${ }^{17}$.

Azo dyes $(-\mathrm{N}=\mathrm{N}-)$ are a class of compounds which have attracted attention over the past few years due to their widespread use as dyeing and pigments and diverse biomedical applications ${ }^{18}$ such as antiviral ${ }^{19}$, antibacterial ${ }^{20}$, antifungal ${ }^{21}$, antitumor ${ }^{22}$, hypotensive, anti-inflammatory and antioxidants etc. ${ }^{23}$. Specifically against viruses, Naicker et al. identified an azo compound as a lead inhibitor of HIV-1 ${ }^{24}$, Farghaly et al. discovered some of the highly active anti-HCV arylazobenzosuberones compared to ribavirin ${ }^{25}$. Moreover, a series of highly active aminoarylazo compounds was evaluated by Tonelli et al. against a panel of RNA viruses ${ }^{26}$.

To our knowledge, no study has been conducted before to evaluate the bioactive potential of azo compounds against avian influenza virus (orthomyxovirus) and newcastle disease virus 
(paramyxovirus). Therefore, based on such evidences, a series of azo derivatives [(E)-1-(1,3dioxolan-2-yl)-2-phenyldiazene] (1), [(E)-1-(1,3-dioxolan-2-yl)-2-(4-methylphenyl)diazene] (2), 2[(E)-phenyldiazenyl]-1H-benzimidazole] (3) , [(E)-1-(1,3-dioxolan-2-yl)-2-(4-ethylphenyl)diazene] (4) and [(E)-1-(1,3-dioxolan-2-yl)-2-(2-methylphenyl)diazene] (5) were synthesized by coupling reaction of diazonium salt solutions with active methylene (1,3-dioxolane and benzimidazole), structural determination was done by ${ }^{1} \mathrm{H}$ NMR and FT-IR spectroscopic analysis, the efficacy of synthesized compounds was assayed by In Ovo antiviral (NDV and AIV) activities and binding interaction was analyzed through molecular docking studies.

\section{MATERIALS AND METHODS}

\subsection{General}

All solvents and chemicals were of analytical grade and purchased from Sigma-Aldrich and Merck. Melting points were determined using a calibrated thermometer by digital melting point apparatus (SMA10 of Stuart Scientific Bibby Sterilin Ltd., UK) and expressed in degrees centigrade $\left({ }^{\circ} \mathrm{C}\right)$. Pre-coated silica TLC plates (60F254 Merck Ltd., Japan) for determining purification, magnetic stirrer (VELP Scientific England) for stirring and micropipettes (ZX58143 and ZX57677) for TLC solvent system were used.

\subsection{Chemistry}

To prepare azo compounds, $25 \mathrm{mM}$ of aqueous $\mathrm{NaNO}_{2}$ was added in equal molar aqueous aniline and the reaction mixture was stirred for 20 minutes at $0{ }^{\circ} \mathrm{C}$, then few drops of $2 \mathrm{M} \mathrm{HCl}$ was added in the reaction mixture at $0{ }^{\circ} \mathrm{C}$ with constant stirring for $3 \mathrm{~h}$. A yellow colored benzene diazonium salt was obtained which was neutralized with $1 \mathrm{M} \mathrm{Na} \mathrm{CO}_{3}$. Then, $25 \mathrm{mM}$ active methylene reagent (1,3-dioxolane) was added drop wise in benzene diazonium chloride solution with constant stirring for 3-4 h until the final product of yellow colored benzene diazonium azo compound was obtained. The product was washed with distilled water and re-crystallized in 30\% methanol solution. Similar procedure was implied in case of benzimidazole as active methylene reagent (Scheme 1).
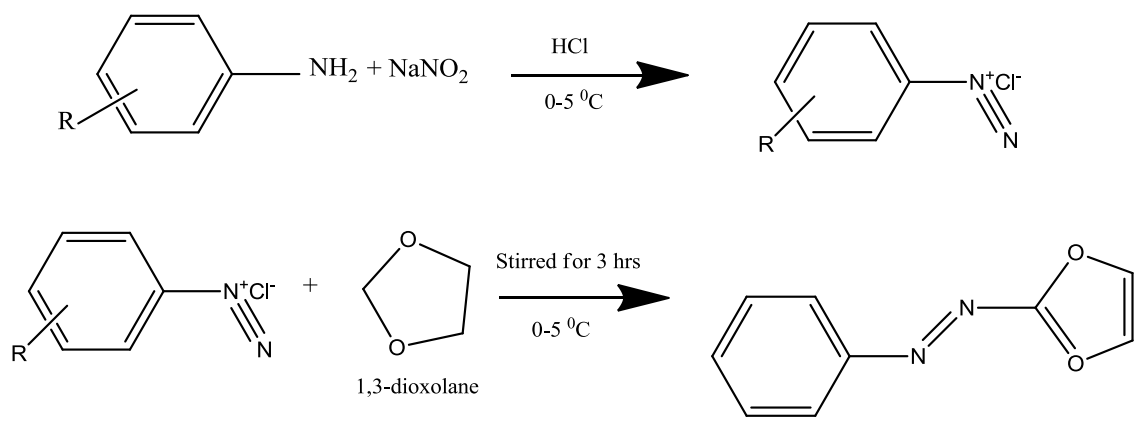


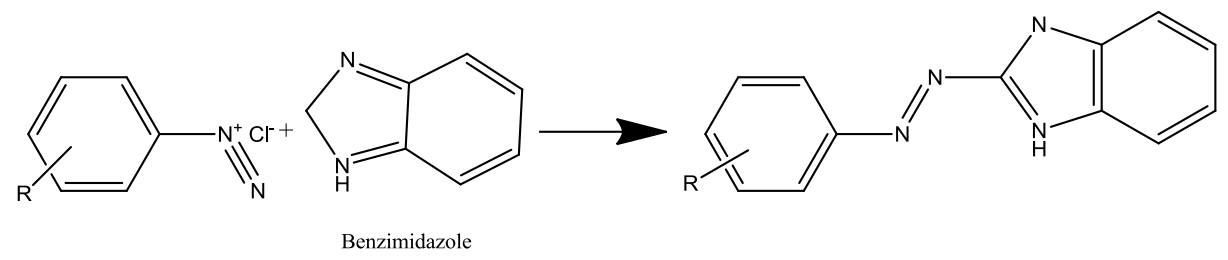

$\left(\mathrm{R}=\mathrm{H}, o-\mathrm{CH}_{3}, p-\mathrm{CH}_{3}, p-\mathrm{C}_{2} \mathrm{H}_{5}\right)$

Scheme 1 General synthesis of azo ligands

\subsection{Spectroscopic Analysis}

The ${ }^{1} \mathrm{H}$ NMR spectra of synthesized compounds were recorded in dimethyl sulfoxide (DMSO)- $d_{6}$ on a Bruker AMX spectrometer operating at $500 \mathrm{MHz}$ and the chemical shifts were expressed in parts per million (ppm) with tetramethylsilane (TMS) as standard. The FTIR spectra were recorded using Bruker IR Tensor 27 (M15E-PS/09) spectrophotometer by ATR sampling technique at range of $4000-600 \mathrm{~cm}^{-1}$.

[(E)-1-(1,3-dioxolan-2-yl)-2-phenyldiazene $](\mathbf{1})$

Dark brown; yield: 65 \%; m.p.: $100{ }^{\circ} \mathrm{C}$; $\mathrm{R}_{f}$ 0.56; Mol. formula: $\mathrm{C}_{9} \mathrm{H}_{10} \mathrm{~N}_{2} \mathrm{O}_{2}$; Mol. mass: 178 g/mol; ${ }^{1} \mathrm{H}$ NMR: $\delta(\mathrm{ppm}), 3.2-3.3\left(\mathrm{~s}, 2 \mathrm{CH}_{2}\right), 4.8(\mathrm{~s}, 1 \mathrm{CH}), 7.0-7.5(\mathrm{~m}, 4 \mathrm{CH}) ; \mathrm{IR}\left(\mathrm{cm}^{-1}\right), 1409(\mathrm{~N}=\mathrm{N}), 1020$ (C-O), $1183(\mathrm{C}-\mathrm{N}), 3010(\mathrm{C}-\mathrm{H})$

[(E)-1-(1,3-dioxolan-2-yl)-2-(4-methylphenyl)diazene $](2)$

Brown; yield: $72 \%$; m.p.: $121^{\circ} \mathrm{C}$; $\mathrm{R}_{f}$ : 0.62; Mol. formula: $\mathrm{C}_{10} \mathrm{H}_{12} \mathrm{~N}_{2} \mathrm{O}_{2}$; Mol. mass: $192 \mathrm{~g} / \mathrm{mol}$; ${ }^{1} \mathrm{H}$ NMR: $\delta(\mathrm{ppm}), 2.32$ (br.s, $\left.1 \mathrm{CH}_{3}\right), 3.2-3.3\left(\mathrm{~s}, 2 \mathrm{CH}_{2}\right), 4.9(\mathrm{~s}, 1 \mathrm{CH}), 7.0-7.5(\mathrm{~m}, 4 \mathrm{CH}) ; \mathrm{IR}\left(\mathrm{cm}^{-1}\right)$, $1440(\mathrm{~N}=\mathrm{N}), 1010(\mathrm{C}-\mathrm{O}), 1186(\mathrm{C}-\mathrm{N}), 2997(\mathrm{C}-\mathrm{H})$.

2-[(E)-phenyldiazenyl]-1H-benzimidazole $](3)$

Light green; yield: 70 \%; m.p.: $186^{\circ} \mathrm{C}$; $\mathrm{R}_{f}$. 0.57; Mol. formula: $\mathrm{C}_{13} \mathrm{H}_{10} \mathrm{~N}_{4}$; Mol. mass: $222 \mathrm{~g} / \mathrm{mol}$; ${ }^{1} \mathrm{H}$ NMR: $\delta(\mathrm{ppm}), 4.8(\mathrm{~s}, 1 \mathrm{CH}), 7.0-7.5(\mathrm{~m}, 4 \mathrm{CH}) ; \mathrm{IR}\left(\mathrm{cm}^{-1}\right), 1502(\mathrm{~N}=\mathrm{N}), 1180(\mathrm{C}-\mathrm{N}), 3028$ (C-H), 3398 (N-H). 
[(E)-1-(1,3-dioxolan-2-yl)-2-(4-ethylphenyl)diazene] (4)

Light brown; yield: $68 \%$; m.p.: $92{ }^{\circ} \mathrm{C}$; $\mathrm{R}_{f}$ : 0.64; Mol. formula: $\mathrm{C}_{11} \mathrm{H}_{14} \mathrm{~N}_{2} \mathrm{O}_{2}$; Mol. mass: 206 $\mathrm{g} / \mathrm{mol} ;{ }^{1} \mathrm{H}$ NMR: $\delta(\mathrm{ppm}), 1.2-2.6\left(\mathrm{~d}, 1 \mathrm{CH}_{3}\right), 3.3\left(\mathrm{~s}, 1 \mathrm{CH}_{2}\right), 4.8(\mathrm{~s}, 1 \mathrm{CH}), 7.0-7.5(\mathrm{~m}, 4 \mathrm{CH})$; IR $\left(\mathrm{cm}^{-1}\right), 1442(\mathrm{~N}=\mathrm{N}), 1054(\mathrm{C}-\mathrm{O}), 1191(\mathrm{C}-\mathrm{N}), 2959(\mathrm{C}-\mathrm{H})$.

[(E)-1-(1,3-dioxolan-2-yl)-2-(2-methylphenyl)diazene] (5)

Pinkish; yield: 80 \%; m.p.: $45{ }^{\circ} \mathrm{C}$; Rf: 0.55; Mol. formula: $\mathrm{C}_{10} \mathrm{H}_{12} \mathrm{~N}_{2} \mathrm{O}_{2}$; Mol. mass: $192 \mathrm{~g} / \mathrm{mol}$; ${ }^{1} \mathrm{H}$ NMR: $\delta(\mathrm{ppm}), 2.2-2-4\left(\mathrm{~d}, 1 \mathrm{CH}_{3}\right), 3.3\left(\mathrm{~s}, 1 \mathrm{CH}_{2}\right), 4.8(\mathrm{~s}, 1 \mathrm{CH}), 6.9-7.5(\mathrm{~m}, 4 \mathrm{CH}) ; \mathrm{IR}\left(\mathrm{cm}^{-1}\right)$, $1104(\mathrm{C}-\mathrm{N}), 1055(\mathrm{C}-\mathrm{O}), 1502(\mathrm{~N}=\mathrm{N}), 3090(\mathrm{C}-\mathrm{H})$.

\subsection{Biological Study}

\subsubsection{Cultivation of Viruses}

Embryonated chicken eggs were obtained from the Government Poultry Farm, Bahawalpur. Lasota strain of NDV, AIV H9N2 strain vaccine (Gallimune Flu H9 M.E from Merial Laboratories Italy), were obtained from University College of Veterinary and Animal Sciences, The Islamia University of Bahawalpur. The respective viral strains were inoculated in 7-to -11 days old embryonated eggs through chorio-allantoic route and incubated at $37^{\circ} \mathrm{C}$. The eggs were harvested $48 \mathrm{~h}$ post inoculation (PI), viral titer was estimated as per the method of Sekhar et al. ${ }^{27}$ and the viral stocks were stored at $-40{ }^{\circ} \mathrm{C}$.

\subsubsection{Antiviral Assay}

In Ovo antiviral testing of the title compounds was carried out in developing chick embryos. Nineday-old embryonated chicken eggs were labeled according to the compounds used. The eggs were swabbed with $70 \%$ alcohol and transferred into sterile trays. The swabbed eggs were placed in the micro safety cabinet where they were punched and inoculated with the compound/virus mixture via the allantoic route. The compound/virus mixture was prepared by suspending $0.1 \mathrm{~mL}$ of virus in $0.1 \mathrm{~mL}$ of $1 \mathrm{mg} / \mathrm{mL}$ compound in DMSO. Virus dissolved in saline solution without compounds was used as negative controls. Allantoic fluids were harvested $48 \mathrm{~h}$ PI, for Hemagglutination test to quantify viruses. 


\subsubsection{Hemagglutination (HA) Test}

\subsubsection{Preparation of Red Blood Cell Suspension}

Chicken blood was collected in freshly prepared Alsever's solution and centrifuged at $4000 \mathrm{rpm}$ for 5 min. The supernatant was discarded, and RBCs were washed with 0.1 M PBS (pH 7.4). This step was repeated three times. To prepare $1 \%$ suspension, $10 \mu \mathrm{L}$ of packed cells were dissolved in $1 \mathrm{~mL}$ of 0.1 M PBS. Later, the standard HA test was performed as described by Hirst et al. ${ }^{28}$.

\subsection{Molecular Docking}

The three-dimensional X-ray crystallographic structures of PDB IDs 1 NN2 and 1USX were retrieved from RCSB Protein Data Bank (http://www.rcsb.org/pdb/home/home.do). The docking simulation was performed by virtual screening tool PyRx with VINA wizard approach and PyMOL (0.8) was used for structural representation. Protein preparation was performed by the removal of water, addition of polar hydrogen and kollman charges, processed to the respective .pdbqt file formats. Similarly, ligand preparation was performed by addition of polar hydrogen and gasteiger charges were given, and there was no further adjustment on the ligand torsion tree, accessed to .pdbqt file formats. Grid box was prepared with parameters as follows: grid box center coordinate: 87.320,_9.696,_34.751; box size: $74 \ldots 78$ _ 80; grid point spacing: $0.375 \AA$. The grid box was adjusted so that the ligand moved freely in search space within the binding pocket residues. After the optimized conditions were set, compound (5) and oseltamivir were docked with respective viral proteins (1NN2 and 1USX) and the best binding conformation with minimum binding energy ( $\mathrm{kcal} / \mathrm{mol})$ was used for visualization using PyMOL.

\section{RESULTS AND DISCUSSION}

3.1. Chemistry

The detailed interpretation of IR spectra of synthesized compounds indicated the formation of azo compounds as the absence of $\mathrm{NH}_{2}$ peak at $3600-3400 \mathrm{~cm}^{-1}$, appearance of $\mathrm{N}=\mathrm{N}$ peak at $1530-1440$ $\mathrm{cm}^{-1}, \mathrm{C}-\mathrm{O}$ peak at $1100-1050 \mathrm{~cm}^{-1}, \mathrm{C}-\mathrm{N}$ peak at $1200-1100 \mathrm{~cm}^{-1}$ and $\mathrm{C}-\mathrm{H}$ peak at $3100-3000 \mathrm{~cm}^{-1}$ was observed. Similarly, the ${ }^{1} \mathrm{H}$ NMR analysis elucidated the concerned proton peaks in expected regions which confirmed the synthesis of azo compounds. The peaks observed at: 3.2-3.3 ppm for $\mathrm{CH}_{2}$ (1,3-dioxolane), $4.8 \mathrm{ppm}$ for $\mathrm{CH}$ protons and multiplet between 7.0-7.5 ppm for phenyl 
protons confirmed the synthesis of [(E)-1-(1,3-dioxolan-2-yl)-2-phenyldiazene] (1). Similarly, peaks at 2.34 ppm for $p-\mathrm{CH}_{3}, 3.2-3.3 \mathrm{ppm}$ for $\mathrm{CH}_{2}, 4.9 \mathrm{ppm}$ for $\mathrm{CH}$ protons and multiplet between 7.0-7.5 ppm for phenyl protons confirmed synthesis of [(E)-1-(1,3-dioxolan-2-yl)-2-(4methylphenyl)diazene] (2). The ${ }^{1} \mathrm{H}$ NMR spectra observed at: $4.8 \mathrm{ppm}$ for $\mathrm{CH}$ and 7.0-7.5 ppm for phenyl protons confirmed 2-[(E)-phenyldiazenyl]-1H-benzimidazole] (3). The peaks observed at: 1.2-2.6 ppm for $\mathrm{CH}_{3}, 3.3 \mathrm{ppm}$ for $\mathrm{CH}_{2}, 4.8 \mathrm{ppm}$ for $\mathrm{CH}$ and 7.0-7.5 ppm for phenyl protons respectively confirmed the ${ }^{1} \mathrm{H}$ NMR shifts of [(E)-1-(1,3-dioxolan-2-yl)-2-(4-ethylphenyl)diazene] (4). In case of [(E)-1-(1,3-dioxolan-2-yl)-2-(2-methylphenyl)diazene] (5), ${ }^{1} \mathrm{H}$ NMR shifts predicted the peaks at: 2.2-2.4 ppm for $o-\mathrm{CH}_{3}, 3.3 \mathrm{ppm}$ for $2 \mathrm{CH}_{2}, 4.8 \mathrm{ppm}$ for $\mathrm{CH}$ and multiplet between 6.9$7.5 \mathrm{ppm}$ for phenyl protons respectively. The IR and ${ }^{1} \mathrm{H}$ NMR spectra of azo compound (5) are shown in Fig. (1 \& 2), while, the spectra of azo compounds (1-4) are given in supplementary file.

\subsection{Biological Study}

All eggs were inoculated with virus control, the results of Hemagglutination (HA) test in case of anti-NDV potential of azo compounds (Fig. 3) revealed that azo compound (5) actively inhibited the viral propagation $(100 \%$ at $0.1 \mathrm{mg} / 100 \mu \mathrm{L})$ while compounds (3) and (4) inhibit $50 \%$ of viral growth at given concentration. However, the tested compounds (1) and (2) were found inactive in this regard. Similarly, in case of anti-AIV activity of azo compounds, only compounds (3) (40\% at $0.1 \mathrm{mg} / 100 \mu \mathrm{L})$ and $(5)(100 \%$ at $0.1 \mathrm{mg} / 100 \mu \mathrm{L})$ were able to kill viral population. It was found that compound (5) has maximum potential to inhibit both viruses i.e. NDV and AIV. With the decrement of concentration i.e. $0.01 \mathrm{mg} / 100 \mu \mathrm{L}$, compound (5) showed $50 \%$ activity against both viruses (Table 1). Therefore, the initial screening data suggested further analysis of most potent compound (5) by docking simulation against viral proteins of NDV and AIV (H9N2).

\subsection{Docking Study}

To understand the interaction, blind docking studies of tested compound (5) to the crystal structures of N2-subtype of avian influenza virus (PDB code: 1NN2) and hemagglutinin-neuraminidase dimer of newcastle disease virus (PDB code: 1USX), were conducted and the generated docked complexes were examined on the basis of minimum energy values ( $\mathrm{kcal} / \mathrm{mol})$, bonding interactions such as hydrogen and hydrophobic bonds respectively. Oseltamivir was used as comparative binding interaction analysis ${ }^{29}$. The best conformational docked pose of azo (5) with binding affinity $-6.9 \mathrm{kcal} / \mathrm{mol}$ is shown in Fig. 4, which showed that both nitrogen atoms of azo moiety and oxygen atom from 1,3-dioxolane formed strong hydrogen bonds with Arg283, Asp355 and Asn356 
with bond lengths of 2.96, 3.77 and $3.59 \AA$, respectively. Similarly, hydrophobic interactions were seen between methyl-phenyl ring of azo (5) and Ser88, Pro285, Pro282, Arg283 and Asn356 with bond lengths $3.27,3.32,3.21,3.87$ and $3.27 \AA$. However, a $\pi-\pi$ interaction was observed between carbon atoms of 1,3-dioxolane ring and Tyr283 with bond length $3.29 \AA$. In case of oseltamivir1NN2 docked complex (Fig. 4), hydrogen bonding was observed between nitrogen atom of acetamido ring and Val127 with bond length of $3.27 \AA$ with binding affinity $-6.5 \mathrm{kcal} / \mathrm{mol}$, while, hydrophobic interactions were seen among the carbon atoms of oxy-cyclohexene ring and residues Cys124, Cys129 and Val412 with bond lengths 3.89, 3.54 and $3.64 \AA$ respectively

The docking results of azo ligand (5)-1USX (Fig. 5) suggested that hydrogen bonding exist between nitrogen atom of azo moiety and Asn161 and Pro164 with bond lengths 3.13 and $3.02 \AA$, however, the nitrogen and oxygen atoms of 1,3-dioxolane showed weak interactions with Pro164 and a $\pi-\pi$ bond was observed between carbon atoms of 1,3-dioxolane and Tyr205 and Ser226 with binding affinity $-8.0 \mathrm{kcal} / \mathrm{mol}$. Similarly, the docked complex of oseltamivir-1USX (free binding energy -7.5 kcal/mol) has shown (Fig. 5) that nitrogen atoms of 4-acetamido and 5-amino rings were involved in hydrogen bonding with residues Ileu136 and Gly137 with bond lengths 3.13 and $2.7 \AA$, whereas carboxylate moiety made hydrophobic interaction with Ala182 and oxy-cyclohexene ring made other interactions with residues Ala182, Lys138 and Thr406. Literature has suggested that hydrogen bonds play an important role in molecular docking because they stabilize and strengthen the docked complexes ${ }^{30,31}$. It is therefore, inferred that the substitution of $-\mathrm{CH}_{3}$ group at ortho position has given the perfect geometry to the small structural molecule of azo compound (5) with maximum antiviral effect, hence, the comparative binding energy and interaction analysis has shown significance of compound (5) over standard drug oseltamivir.

\section{CONCLUSION}

The azo compounds were successfully synthesized under facile conditions and were obtained in good yields. It can be inferred from the results of bioactivity and computational studies that the azo compound (5) can be further analyzed against other influenza viral strains and can be served as a structural template in designing of novel antiviral agents since there are less synthetic antiviral drugs available commercially.

\section{ACKNOWLEDGEMENTS}

The authors are grateful to the Department of Chemistry, Department of Biochemistry \& Biotechnology and University College of Veterinary and Animal Sciences, The Islamia University of Bahawalpur, Pakistan for co-operation and assistance throughout the project. 


\section{CONFLICT OF INTEREST}

The authors declare no conflict of interest.

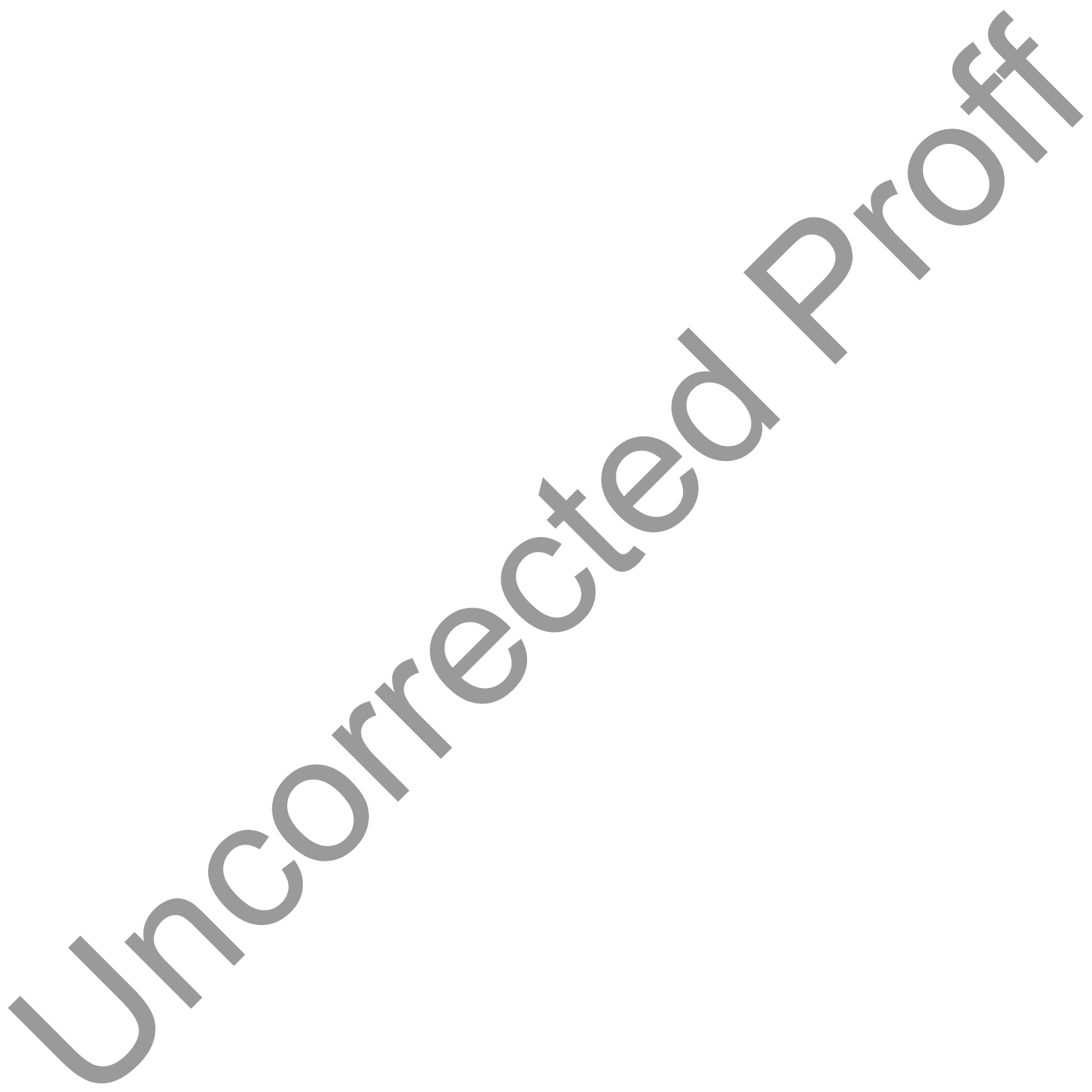




\section{Tables \& Figures}

Table 1 Antiviral potential of azo compounds

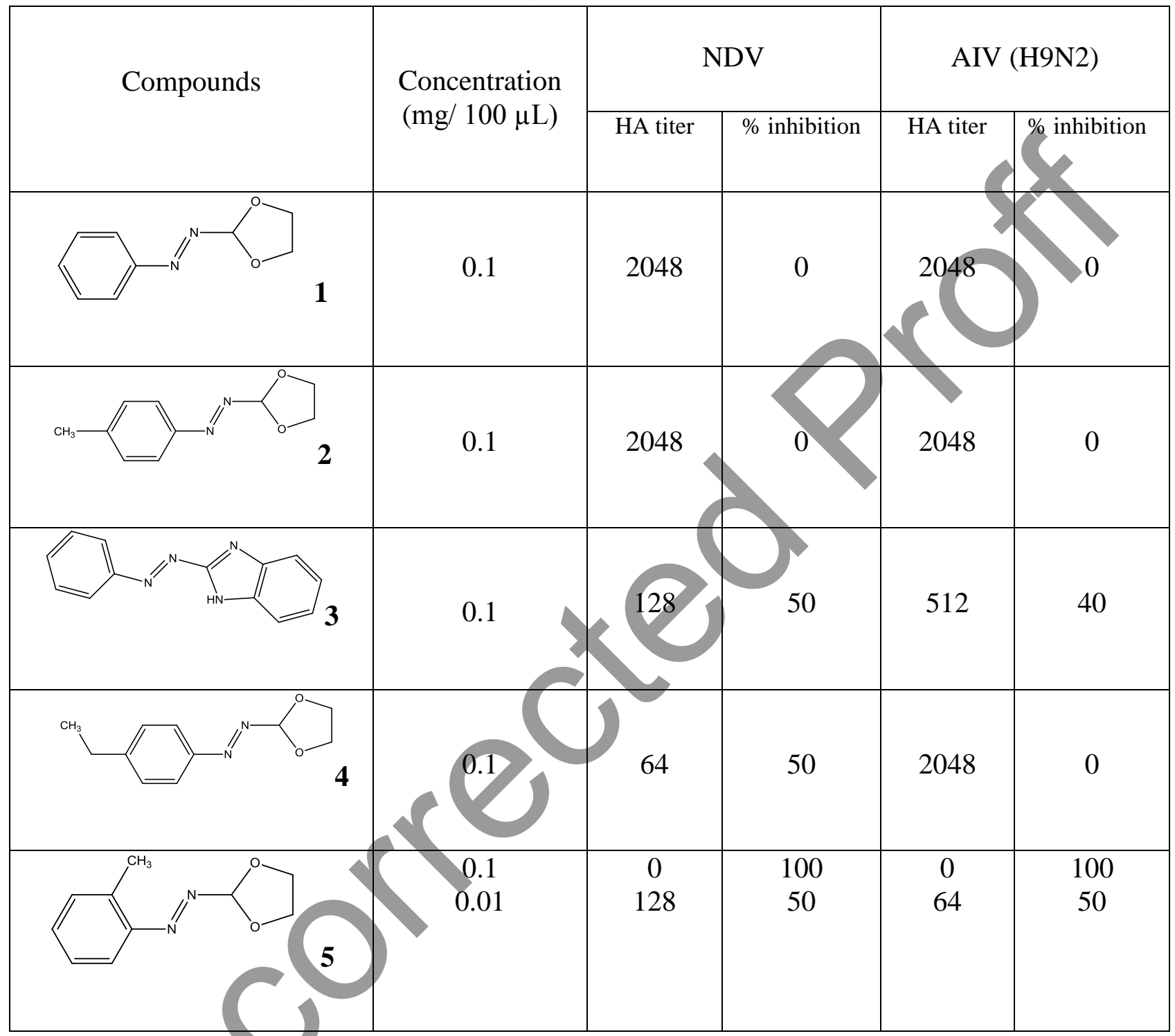




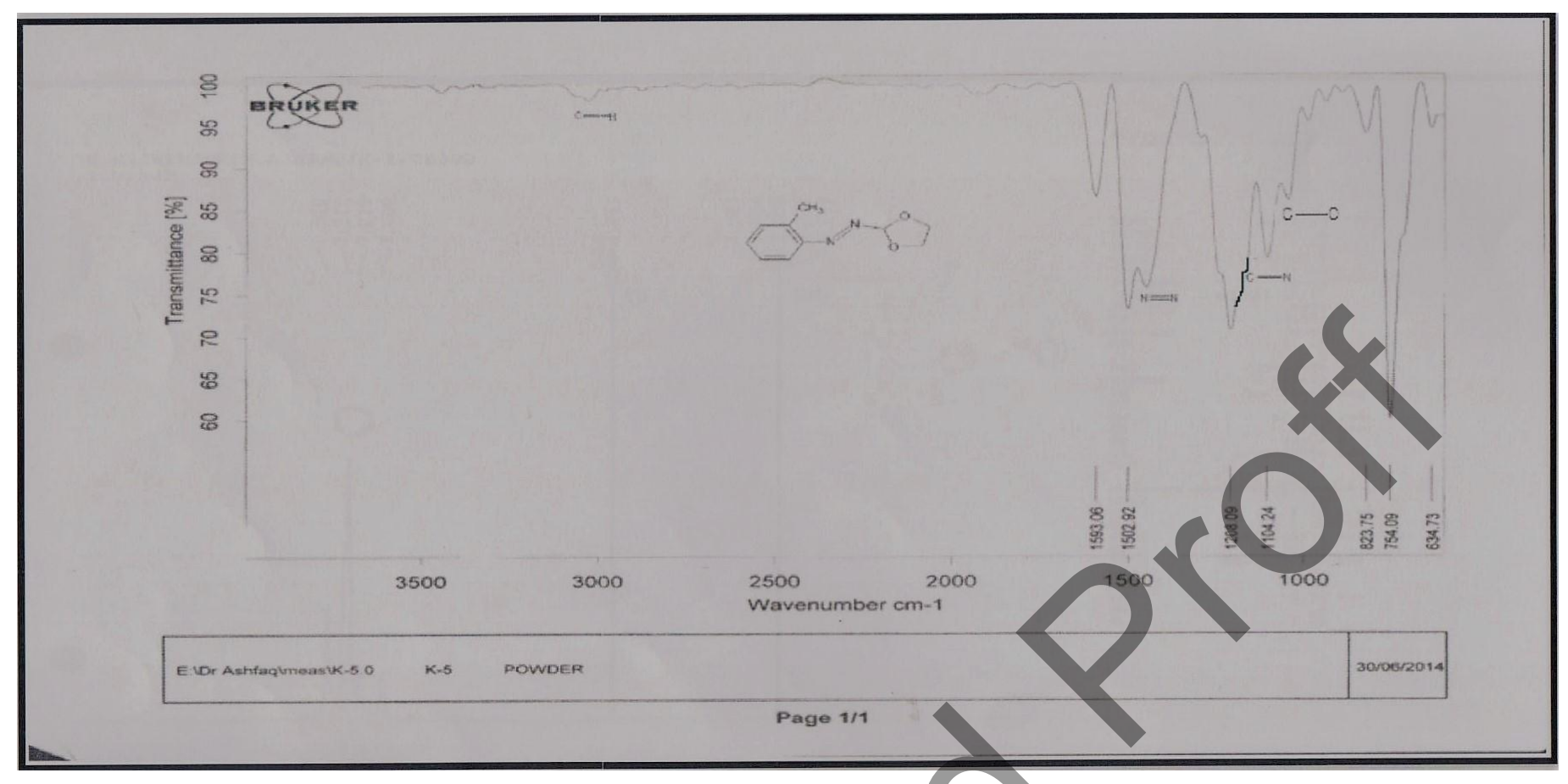

Figure 1 IR spectra of azo compound (5).

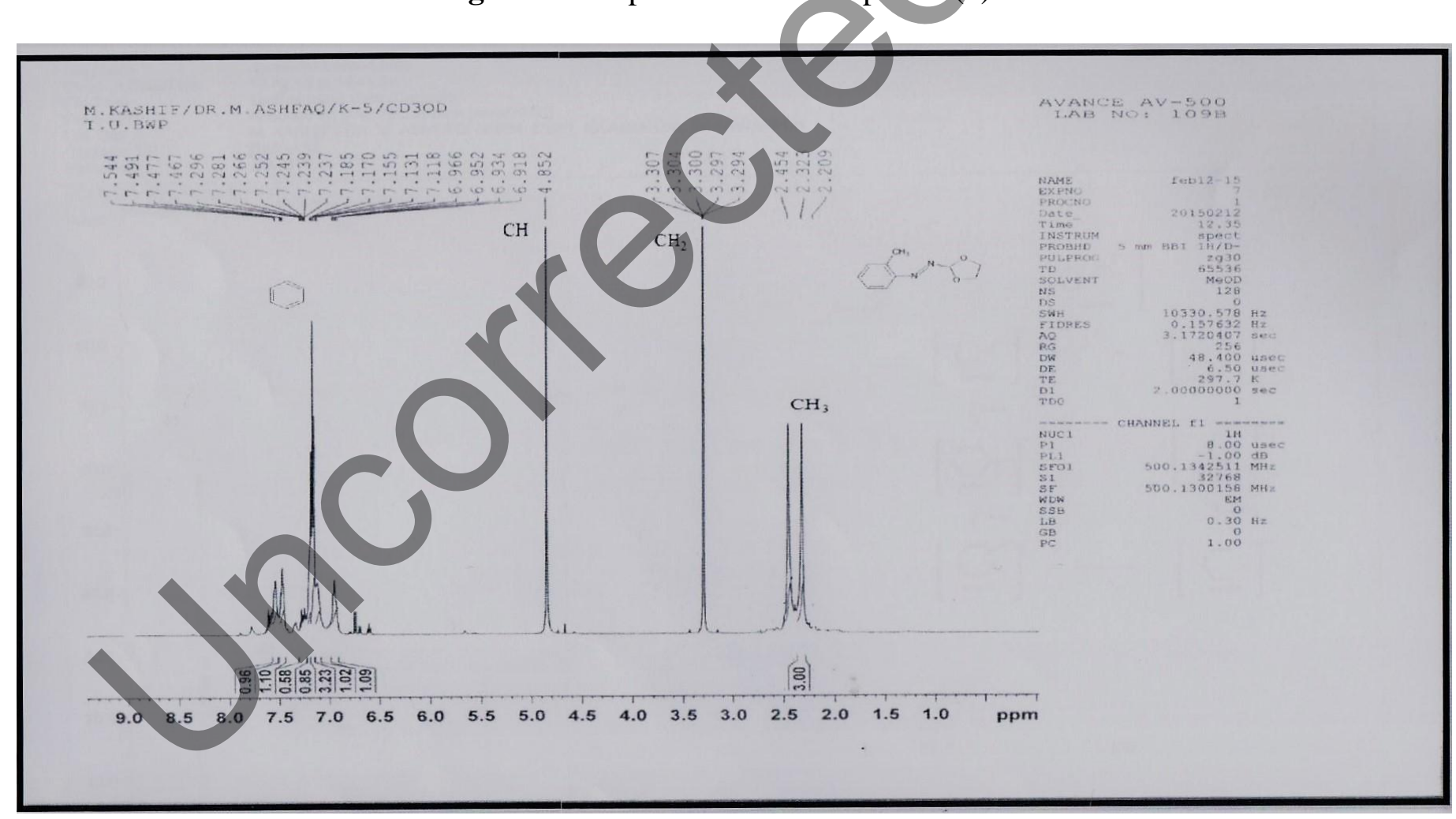

Figure $2 \quad{ }^{1} \mathrm{H}$ NMR chemical shifts of azo compound (5). 


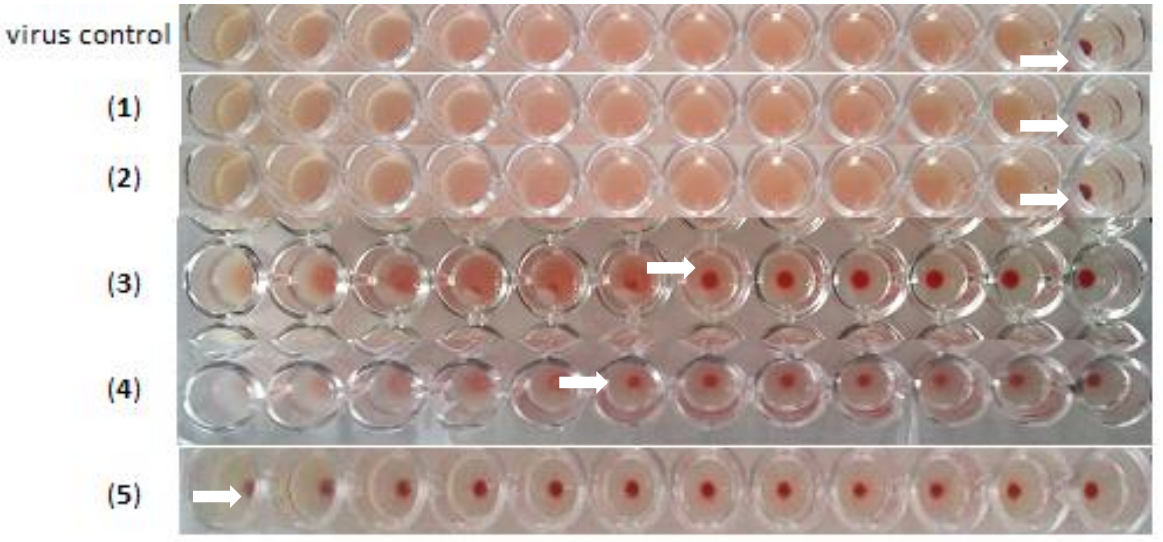

$H A=2048$

$\mathrm{HA}=2048$

$\mathrm{HA}=2048$

$H A=128$
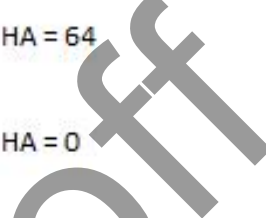

Figure 3 HA test results of azo compounds (1-5) against NDV at $0.1 \mathrm{mg} / 100 \mu \mathrm{L}$.

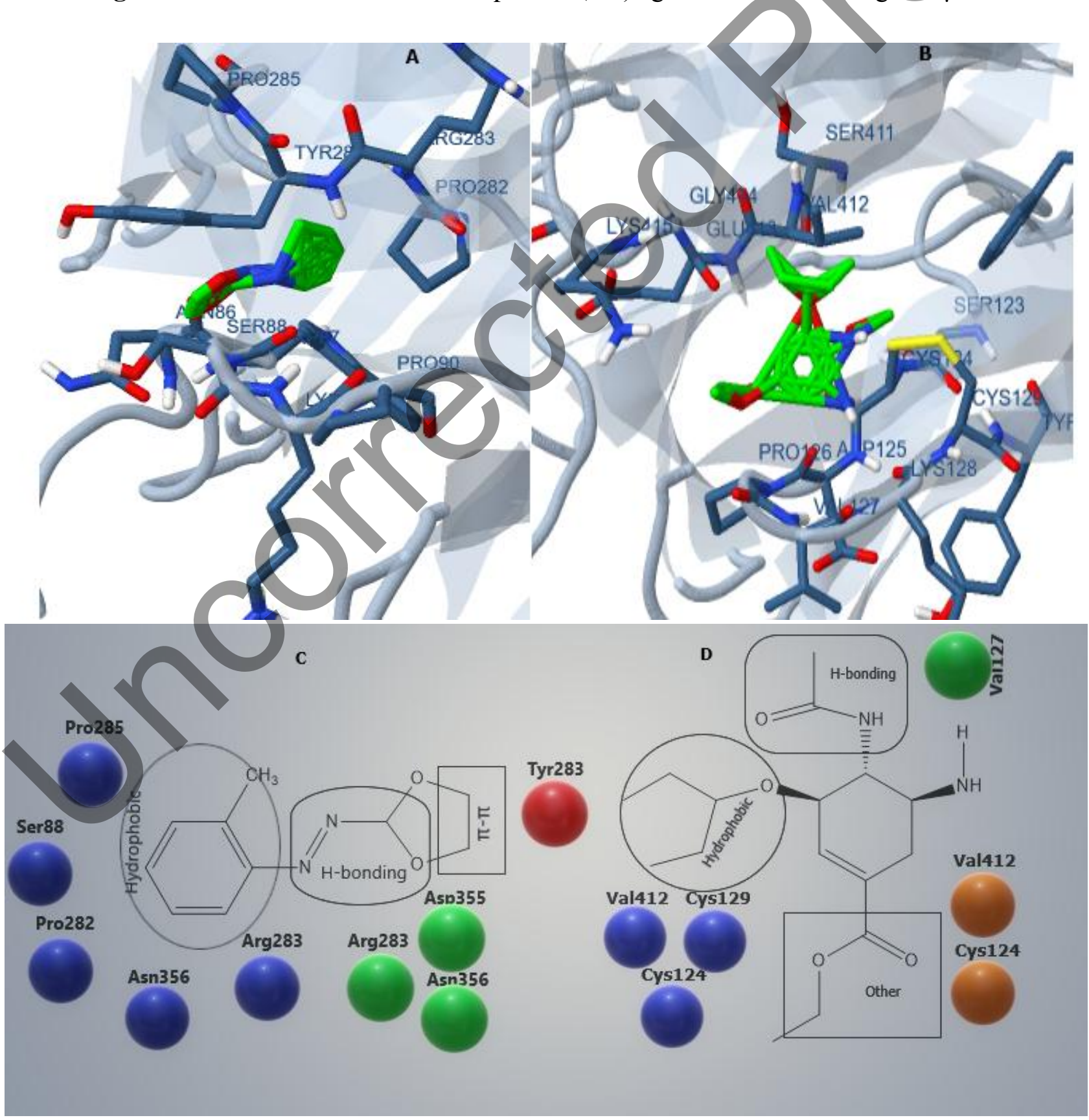


Figure 4 (A). Structural representation of docking complex of azo ligand (5) (sticks with carbon atoms shown as: green, nitrogen: blue and oxygen: red) with interacting side chain residues of neuraminidase (PDB code: 1NN2) shown as dark blue cylinders. (B). key residues in contact with oseltamivir (green sticks). (C). Structural interactions exhibited by azo ligand (5). (D). Interaction shown by components of oseltamivir.

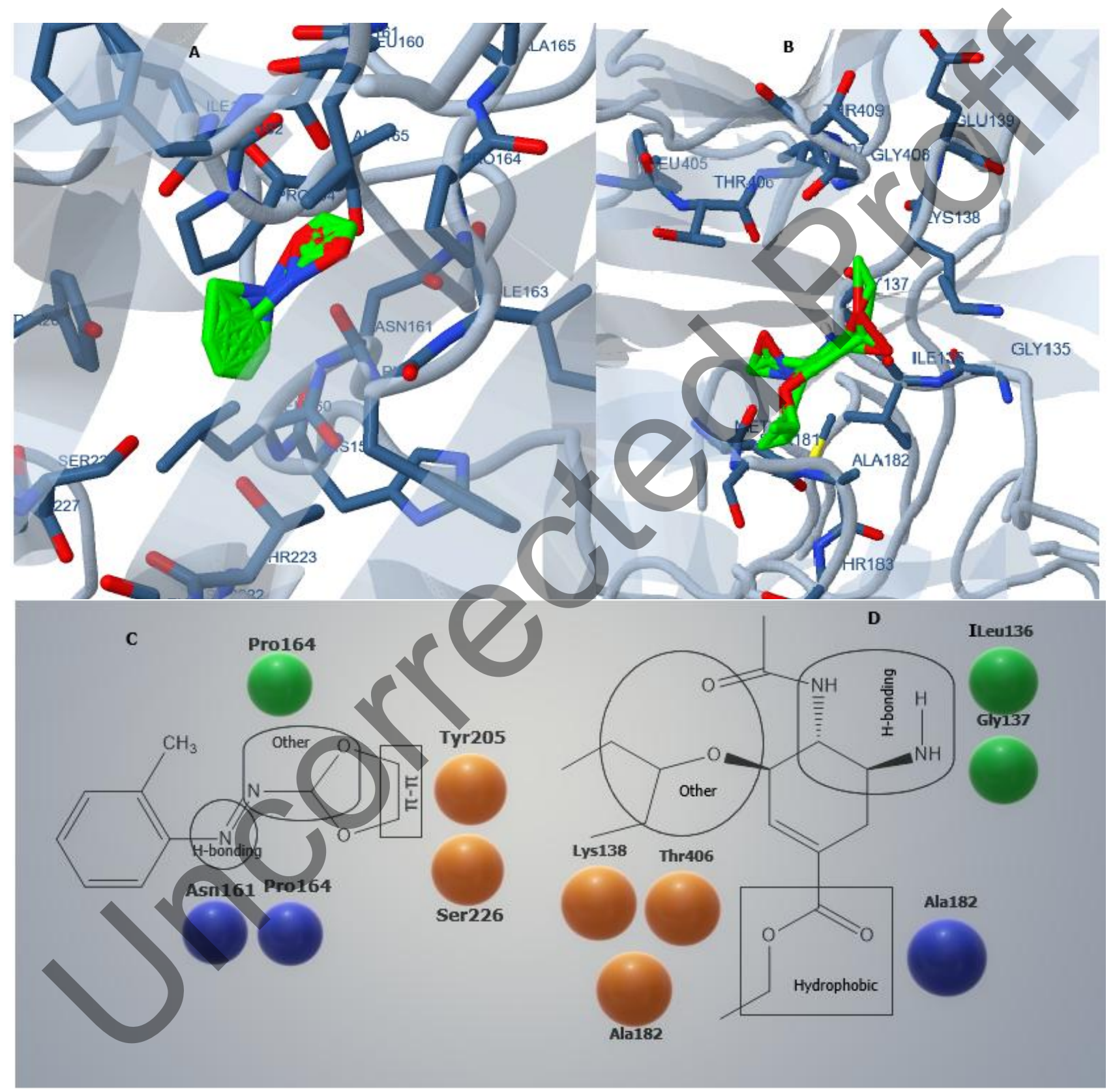

Figure 5 (A). Docking complex of HN dimer of newcastle disease virus (PDB code: 1USX) with best pose of azo ligand (5) against target residues. (B). The closer view of binding pocket interaction with best conformation position of oseltamivir against target residues. (C). key interactive components observed in ligand (5)-1USX complex. (D). structural features of oseltamivir docked with 1USX. 


\section{References}

1. Mahesar S A, Sherazi S T H, Niaz A, Bhanger M I, uddin S, Rauf A. Simultaneous assessment of zinc, cadmium, lead and copper in poultry feeds by differential pulse anodic stripping voltammetry. Food Chem Toxicol. 2010; 48:2357-60.

2. Zaitsev V, von Itzstein M, Groves D, Kiefel M, Takimoto T, Portner A, Taylor G. Second sialic acid binding site in Newcastle disease virus hemagglutinin-neuraminidase: implications for fusion. J Vir. 2004; 78:3733-41.

3. Chintakrindi A, D'souza C, Kanyalkar M. Rational development of neuraminidase inhibitor as novel anti-flu drug. Mini Rev Med Chem. 2012; 12:1273-81.

4. Shaw Stewart P D. Seasonality and selective trends in viral acute respiratory tract infections. Med Hypo. 2016; 86:104-19.

5. Beltra J-C, Decaluwe H. Cytokines and persistent viral infections. Cytokine. 2016; 82:4-15.

6. Crennell S, Takimoto T, Portner A, Taylor G. Crystal structure of the multifunctional paramyxovirus hemagglutinin-neuraminidase. N Struct Mol Bio. 2000; 7:1068.

7. Ganar K, Das M, Sinha S, Kumar S. Newcastle disease virus: Current status and our understanding. Virus Res. 2014; 184:71-81.

8. Spackman E, Pantin-Jackwood M J. Practical aspects of vaccination of poultry against avian influenza virus. Vet J. 2014; 202:408-15.

9. Yang J, Li M, Shen X, Liu S. Influenza A virus entry inhibitors targeting the hemagglutinin. Viruses. 2013; 5:352-73.

10. Jackson R J, Cooper K L, Tappenden P, Rees A, Simpson E L, Read R C, Nicholson K G. Oseltamivir, zanamivir and amantadine in the prevention of influenza: A systematic review. J Infect. 2011; 62:14-25.

11. Song J M, Park K D, Lee K H, Byun Y H, Park J H, Kim S H, Kim J H, Seong B L. Biological evaluation of anti-influenza viral activity of semi-synthetic catechin derivatives. Antivir Res. 2007; 76:178-85.

12. Hu J, Asbury T, Achuthan S, Li C, Bertram R, Quine J R, Fu R, Cross T A. Backbone structure of the amantadine-blocked trans-membrane domain M2 proton channel from influenza A virus. Biophy J. 2007; 92:4335-43.

13. Rahn J, Hoffmann D, Harder T C, Beer M. Vaccines against influenza A viruses in poultry and swine: Status and future developments. Vaccine. 2015; 33:2414-24. 
14. Ju H, Zhang J, Sun Z, Huang Z, Qi W, Huang B, Zhan P, Liu X. Discovery of C-1 modified oseltamivir derivatives as potent influenza neuraminidase inhibitors. Eur J Med Chem. 2018; 146:220-31.

15. Lupini C, Cecchinato M, Scagliarini A, Graziani R, Catelli E. In vitro antiviral activity of chestnut and quebracho woods extracts against avian reovirus and metapneumovirus. Res Vet Sci. 2009; 87:482-7.

16. Bantia S, Parker C, Ananth S, Horn L, Andries K, Chand P, Kotian P, Dehghani A, El-Kattan Y, Lin T. Comparison of the anti-influenza virus activity of RWJ-270201 with those of oseltamivir and zanamivir. Antimicrob Agents Chemo. 2001; 45:1162-7.

17. Stratton C F, Newman D J, Tan D S. Cheminformatic comparison of approved drugs from natural product versus synthetic origins. Bioorg Med Chem Lett. 2015; 25:4802-7.

18. Abdallah S M. Metal complexes of azo compounds derived from 4-acetamidophenol and substituted aniline. Arab J Chem. 2012; 5:251-6.

19. Tevyashova A N, Shtil A A, Olsufyeva E N, Luzikov Y N, Reznikova M I, Dezhenkova L G, Isakova E B, Bukhman V M, Durandin N A, Vinogradov A M, Kuzmin V A, Preobrazhenskaya M N. Modification of olivomycin A at the side chain of the aglycon yields the derivative with perspective antitumor characteristics. Bioorg Med Chem. 2011; 19:7387-93.

20. Khanmohammadi H, Pass M, Rezaeian K, Talei G. Solvatochromism, spectral properties and antimicrobial activities of new azo-azomethine dyes with N2S2O2 donor set of atoms. J Mol Struct. 2014; 1072:232-7.

21. Mahata D, Mandal S M, Bharti R, Gupta V K, Mandal M, Nag A, Nando G B. Self-assembled cardanol azo derivatives as antifungal agent with chitin-binding ability. Int $\mathrm{J}$ Bio Macromol. 2014; 69:5-11.

22. Gouda M A, Eldien H F, Girges M M, Berghot M A. Synthesis and antitumor evaluation of thiophene based azo dyes incorporating pyrazolone moiety. J Saudi Chem. Soc. 2016; 20:151-7.

23. Shridhar A H, Keshavayya J, Peethambar S K, Joy Hoskeri H. Synthesis and biological activities of Bis alkyl 1,3,4-oxadiazole incorporated azo dye derivatives. Arab J Chem. 2016; 9, Supplement 2:S1643-S8.

24. Naicker K P, Jiang S, Lu H, Ni J, Boyer-Chatenet L, Wang L-X, Debnath A K. Synthesis and anti-HIV-1 activity of 4-[4-(4,6-bisphenylamino-[1,3,5]triazin-2-ylamino)-5-methoxy-2methylphenylazo]-5-hydroxynaphthalene-2,7-disulfonic acid and its derivatives. Bioorg Med Chem. 2004; 12:1215-20. 
25. Farghaly T A, Abdalla M M. Synthesis, tautomerism, and antimicrobial, anti-HCV, anti-SSPE, antioxidant, and antitumor activities of arylazobenzosuberones. Bioorg Med Chem. 2009; 17:8012-9.

26. Tonelli M, Vazzana I, Tasso B, Boido V, Sparatore F, Fermeglia M, Paneni M S, Posocco P, Pricl S, Colla P L, Ibba C, Secci B, Collu G, Loddo R. Antiviral and cytotoxic activities of aminoarylazo compounds and aryltriazene derivatives. Bioorg Med Chem. 2009; 17:4425-40.

27. Sekhar K C, Janardhan A, Kumar Y N, Narasimha G, Raju C N, Ghosh S. Amino acid esters substituted phosphorylated emtricitabine and didanosine derivatives as antiviral and anticancer agents. App Biochem Biotechnol. 2014; 173:1303-18.

28. Hirst G K. The quantitative determination of influenza virus and antibodies by means of red cell agglutination. J Experiment Med. 1942; 75:49-64.

29. McClellan K, Perry C M. Oseltamivir. Drugs. 2001; 61:263-83.

30. Bikadi Z, Demko L, Hazai E. Functional and structural characterization of a protein based on analysis of its hydrogen bonding network by hydrogen bonding plot. Archiv Biochem Biophy. 2007; 461:225-34.

31. McDonald I K, Thornton J M. Satisfying hydrogen bonding potential in proteins. J Mol Bio. 1994; 238:777-93. 


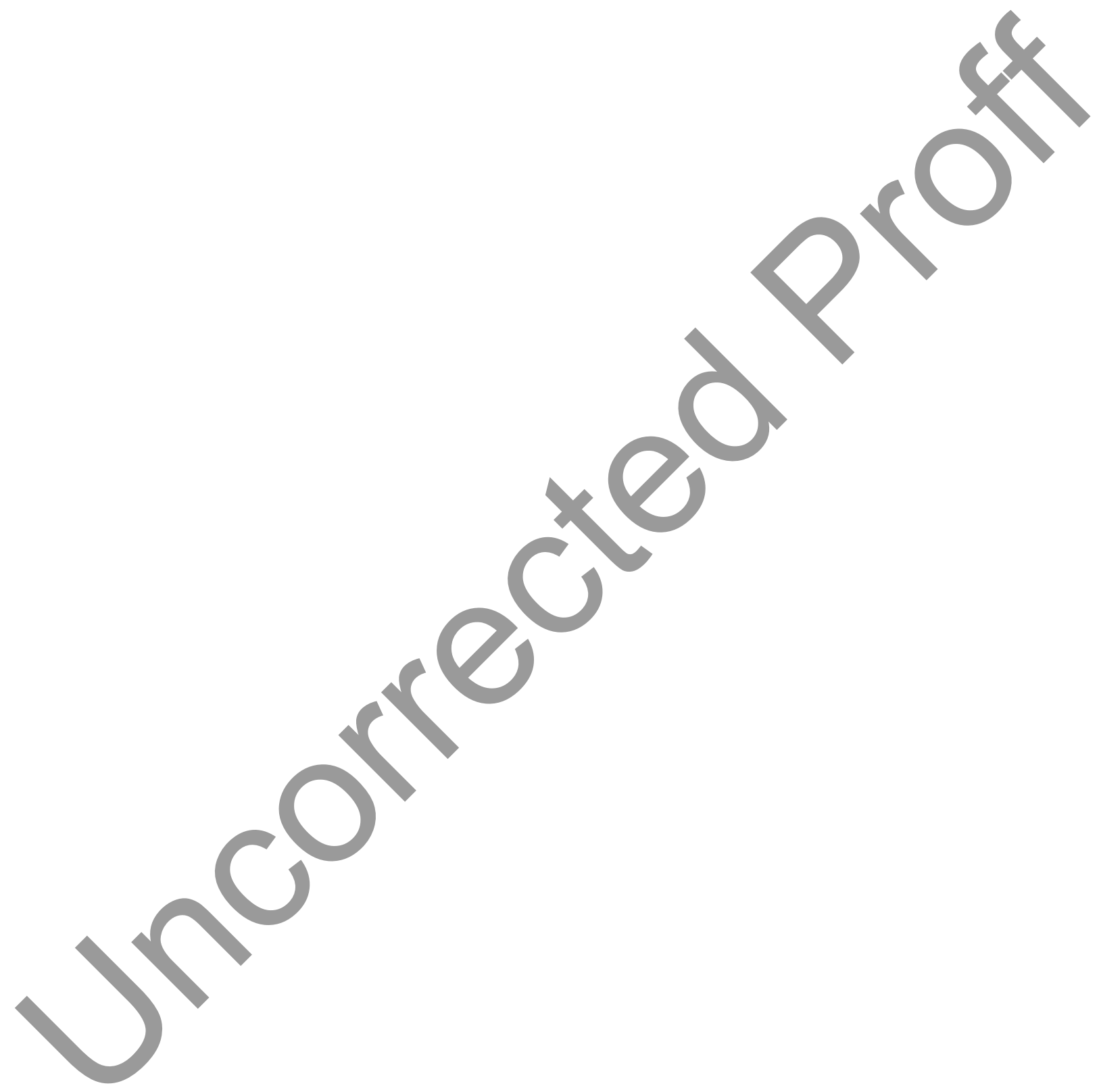

